Corrigendum

\title{
Corrigendum to "4-Phenylbutyric Acid Attenuates Pancreatic Beta-Cell Injury in Rats with Experimental Severe Acute Pancreatitis"
}

\author{
Yu-pu Hong $\mathbb{D},{ }^{1,2}$ Wen-yi Guo, ${ }^{1}$ Wei-xing Wang $\mathbb{D}^{1},{ }^{1}$ Liang Zhao, ${ }^{1,3}$ Ming-wei Xiang, ${ }^{1,3}$ \\ Fang-chao Mei, ${ }^{1,2}$ Ablikim Abliz, ${ }^{1}$ Peng Hu, ${ }^{1}$ Wen-hong Deng, ${ }^{1}$ and Jia Yu ${ }^{1}$ \\ ${ }^{1}$ Department of General Surgery, Renmin Hospital of Wuhan University, 238 Jiefang Road, Wuhan, Hubei Province 430060, China \\ ${ }^{2}$ Key Laboratory of Hubei Province for Digestive System Disease, 9 Zhangzhidong Road, Wuhan, Hubei Province 430060, China \\ ${ }^{3}$ Central Laboratory, Renmin Hospital of Wuhan University, 9 Zhangzhidong Road, Wuhan, Hubei Province 430060, China
}

Correspondence should be addressed to Wei-xing Wang; satellite@163.com

Received 15 October 2017; Accepted 26 October 2017; Published 9 January 2018

Copyright (c) 2018 Yu-pu Hong et al. This is an open access article distributed under the Creative Commons Attribution License, which permits unrestricted use, distribution, and reproduction in any medium, provided the original work is properly cited.

In the article titled "4-Phenylbutyric Acid Attenuates Pancreatic Beta-Cell Injury in Rats with Experimental Severe Acute Pancreatitis" [1], the authors made a mistake in the process of analysis by using the recommended concentrations of reference standard which should be diluted by 20 times to be the actual concentrations.

Therefore, in the "3.3. Serum Insulin, TNF- $\alpha$, IL-1 $\beta$, and Glucose Levels" section, the text reading "Spearman correlation analysis revealed that serum levels of insulin were positively correlated with TNF- $\alpha(r=0.8052, P<0.05)$ and IL-1 $\beta \quad(r=0.7661, \quad P<0.05)$ and showed significantly negative correlation between serum insulin levels and serum glucose levels $(r=-0.7600, P<0.05)$ (Figure 5)" should be corrected as follows.

"Spearman correlation analysis revealed that serum levels of insulin were positively correlated with TNF- $\alpha(r=0.8070$, $P<0.05)$ and IL- $1 \beta(r=0.8270, P<0.05)$ and showed significantly negative correlation between serum insulin levels and serum glucose levels $(r=-0.7191, P<0.05)$ (Figure 5)."

In addition, the raw data for Figures 4 (a) and 5 are included in the Supplementary Materials (available here) and the figures should be corrected as follows. 


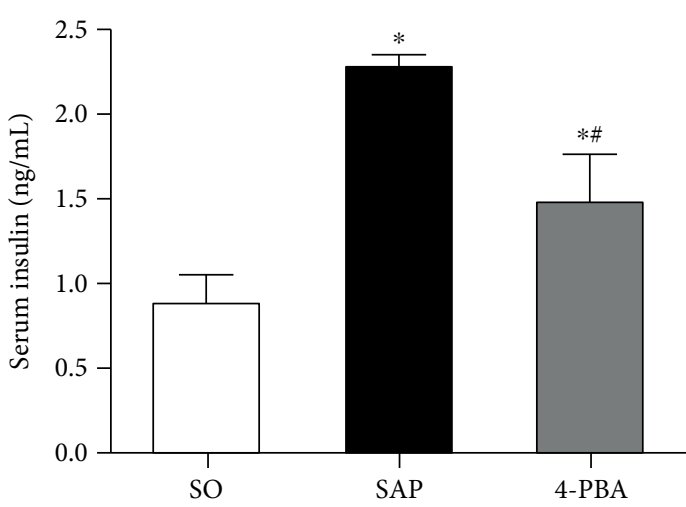

(a)

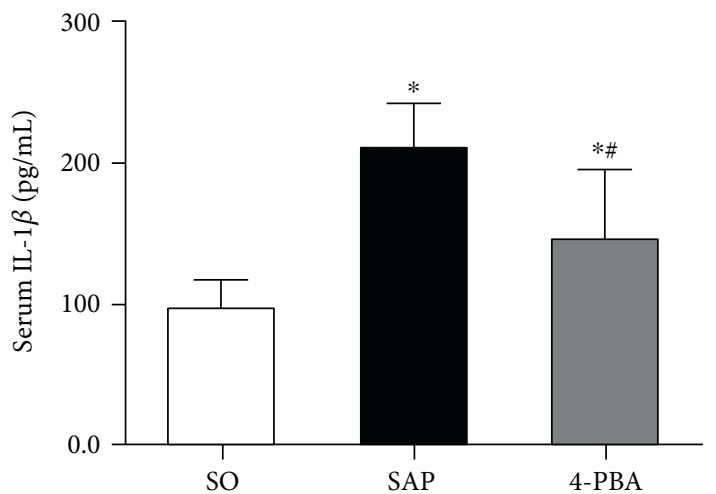

(c)

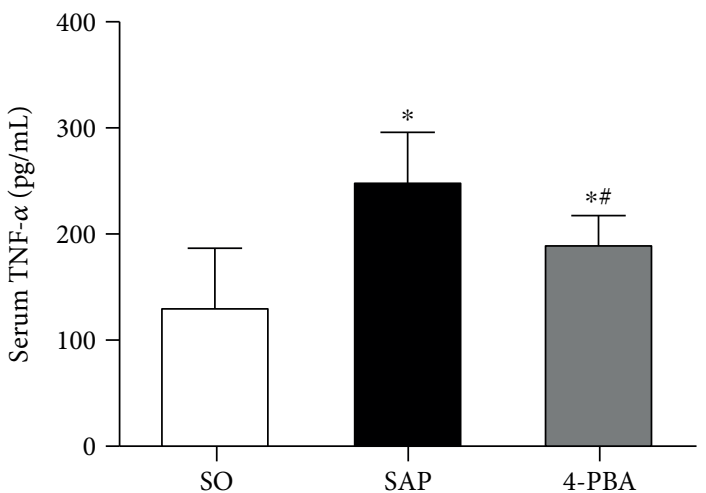

(b)

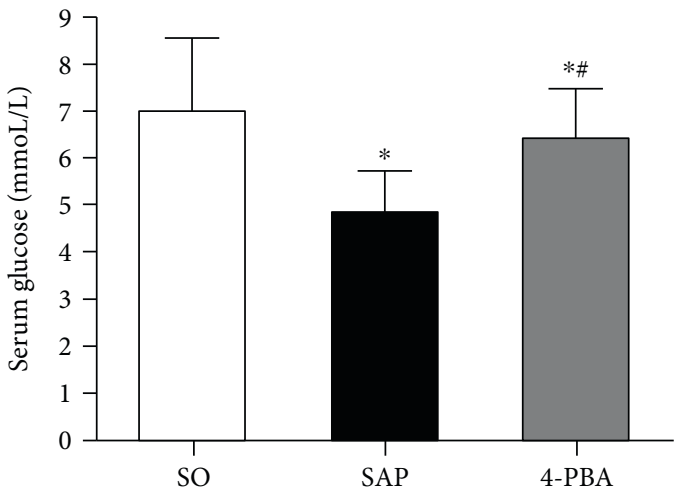

(d)

FIGURE 4: Effects of 4-phenylbutyric acid on insulin, inflammatory cytokine, and glucose production in serum. (a) Insulin; (b) TNF- $\alpha$; (c) IL-1 $\beta$; (d) glucose. Each value represents the mean \pm standard deviation. ${ }^{*} P<0.05$ versus SO group; ${ }^{\#} P<0.05$ versus SAP group. 


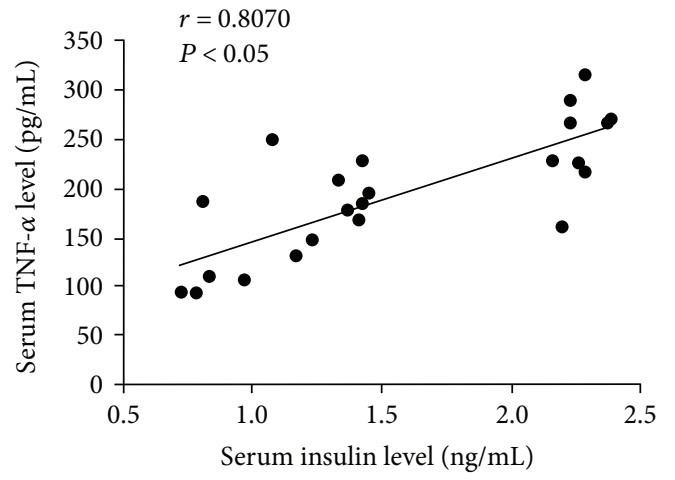

(a)

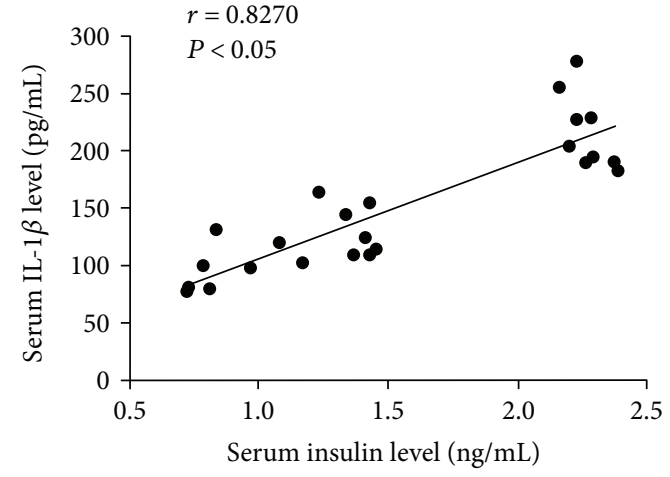

(b)

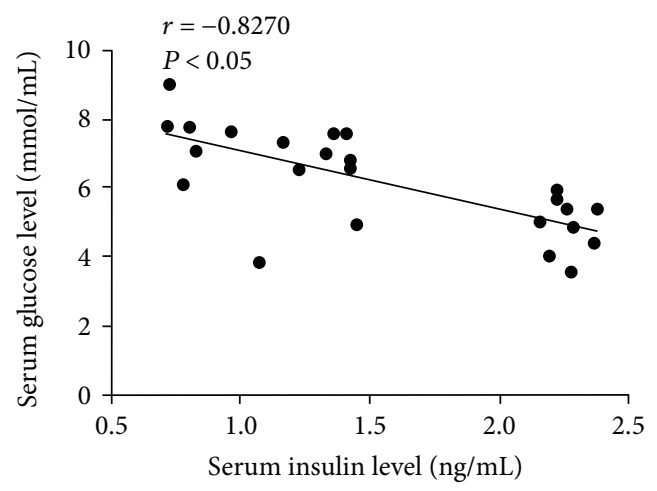

(c)

FIGURE 5: The correlations of serum insulin with TNF- $\alpha$, IL-1 $\beta$, and glucose were analyzed using Spearman correlation test. (a) Spearman correlation between insulin and TNF- $\alpha$; (b) Spearman correlation between insulin and IL-1 $\beta$; (c) Spearman correlation between insulin and glucose.

\section{Supplementary Materials}

Table 1: serum levels of insulin, TNF- $\alpha$, IL- $1 \beta$, and glucose in rats. (Supplementary Materials)

\section{References}

[1] Y.-p. Hong, W.-y. Guo, W.-x. Wang et al., "4-Phenylbutyric acid attenuates pancreatic beta-cell injury in rats with experimental severe acute pancreatitis," International Journal of Endocrinology, vol. 2016, Article ID 4592346, 11 pages, 2016. 


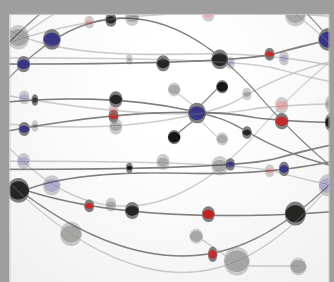

The Scientific World Journal
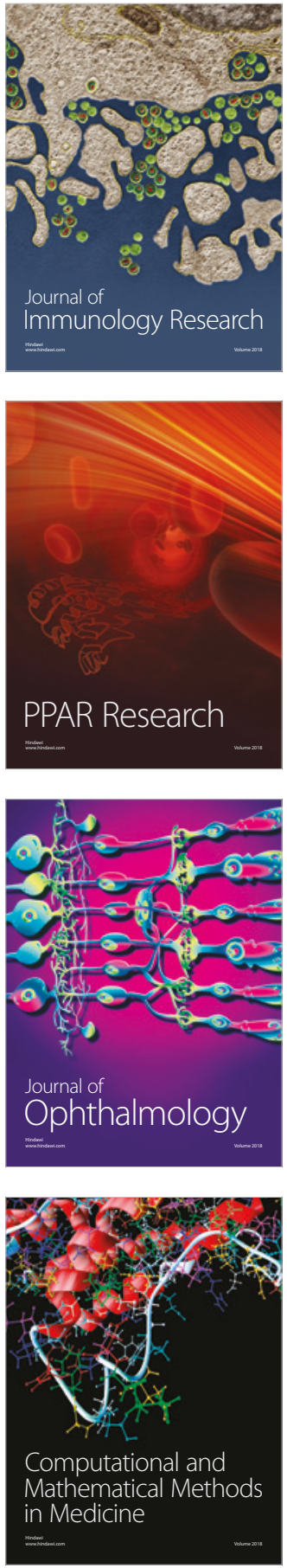

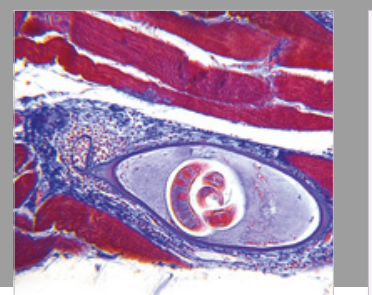

Gastroenterology Research and Practice

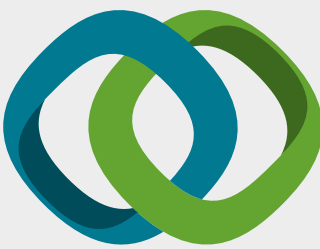

\section{Hindawi}

Submit your manuscripts at

www.hindawi.com
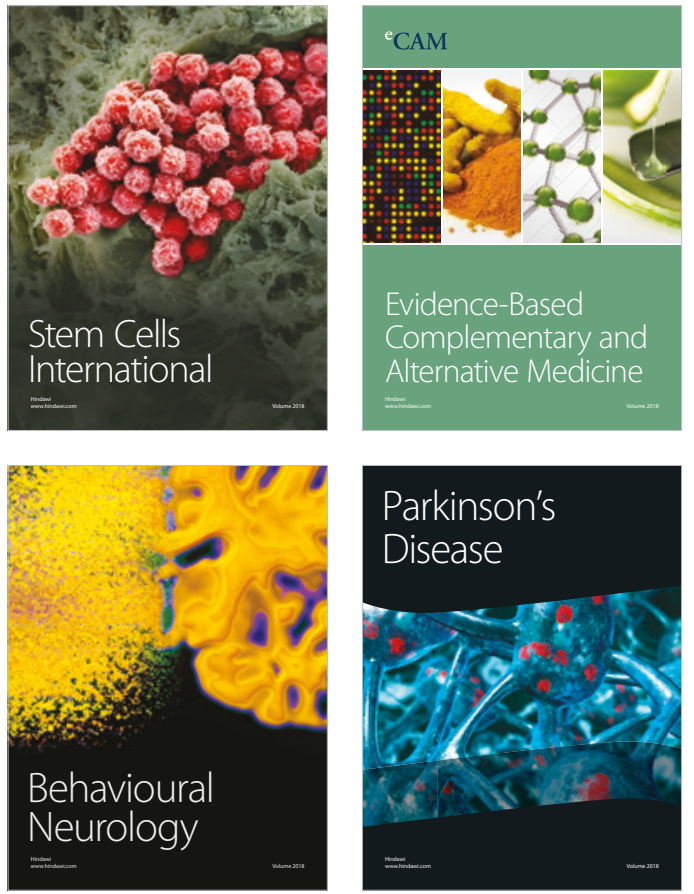

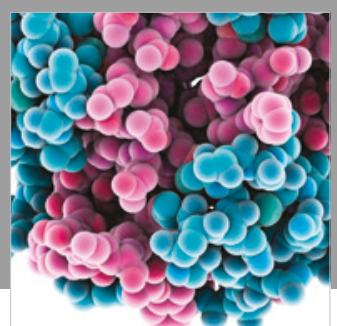

ournal of

Diabetes Research

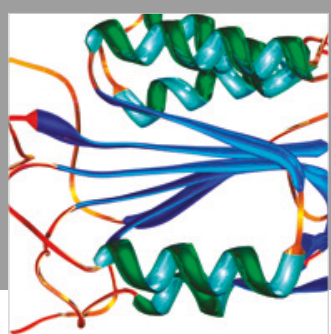

Disease Markers
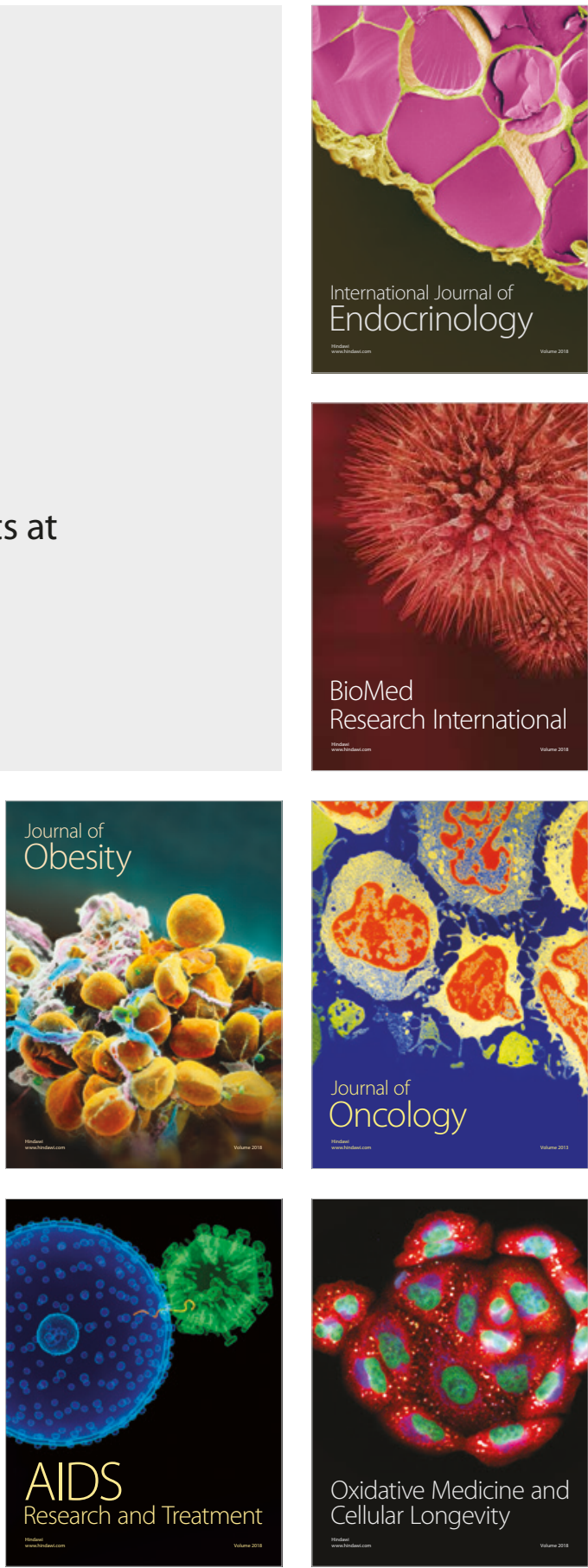